Check for updates

Cite this: Mater. Adv., 2022, 3, 604

Received 22nd October 2021, Accepted 10th November 2021

DOI: $10.1039 / d 1 m a 00983 d$

rsc.li/materials-advances

\title{
Aqueous zinc ion batteries based on sodium vanadate electrode materials with long lifespan and high energy density
}

\author{
Chengkang Luo, ${ }^{a}$ Li Xiao*a and Xiang Wu (D)*ab
}

\begin{abstract}
With the excessive consumption of non-renewable energy sources and subsequent environmental pollution, research focuses have shifted to the development of emerging energy storage devices with desired performance. Aqueous zinc-ion batteries (AZIBs) are expected to become potential alternatives due to their high safety, low cost and environmental friendliness. In this work, we have prepared $\mathrm{Na}_{7} \mathrm{~V}_{7.6} \mathrm{O}_{20} \cdot 4 \mathrm{H}_{2} \mathrm{O}$ (NVO) nanobelts by a facile hydrothermal route. NVO/Zn batteries have been assembled with the as-obtained product as cathodes, which deliver a capacity of $309.4 \mathrm{~mA} \mathrm{~h} \mathrm{~g}^{-1}$ at $0.3 \mathrm{~A} \mathrm{~g}^{-1}$. They maintain excellent cycling stability after 10000 cycles at $10 \mathrm{~A} \mathrm{~g}^{-1}$.
\end{abstract}

\section{Introduction}

It is well known that traditional fossil energy is non-renewable and its overuse will inevitably lead to the quick depletion of energy resources. ${ }^{1-4}$ Therefore, developing emerging energy storage devices is imperative to effectively alleviate the energy crisis. For instance, commercial lithium-ion batteries (LIBs) have been widely used in portable electronic devices such as mobile phones, computers and wearable watches. ${ }^{5,6}$ However, the application of LIBs is largely restricted due to the scarcity of lithium reserves, its high price and poor safety. ${ }^{7,8}$ Therefore, metal ion batteries with high energy densities have attracted widespread attention. ${ }^{9}$ Among the various multivalent ion systems $\left(\mathrm{Al}^{3+10} \mathrm{Mg}^{2+11,12} \mathrm{Ca}^{2+13,14}\right.$ and $\mathrm{Zn}^{2+15}$ ), AZIBs show high theoretical capacity $\left(820 \mathrm{~mA} \mathrm{~h} \mathrm{~g}^{-1}\right)$, low redox potential $\left(-0.76 \mathrm{~V} v s\right.$. SHE) and excellent cycle stability. ${ }^{16}$ Recently, some progress has been achieved in developing cathode materials for ZIBs, such as manganese oxide, ${ }^{17,18}$ vanadium compounds, ${ }^{19,20}$ Prussian blue analogs, ${ }^{21}$ and polyanionic compounds. ${ }^{22}$

Therefore, it is important to further study vanadium-based cathodes because of their high capacity and rich oxidation states. ${ }^{23-25}$ They mainly include $\mathrm{V}_{2} \mathrm{O}_{5},{ }^{26} \quad \mathrm{VO}_{2},{ }^{27}$ and vanadates. ${ }^{28-31}$ However, their poor energy density and sluggish ion transfer speed have not been well resolved. For these reasons, some efforts have been made. In the literature, Wang et al. prepared a composite of $\mathrm{V}_{2} \mathrm{O}_{5}$ and carbon nanotube film $\left(\mathrm{CNF} @ \mathrm{~V}_{2} \mathrm{O}_{5}\right)$. The as-assembled device delivers a specific

\footnotetext{
${ }^{a}$ School of Materials Science and Engineering, Shenyang University of Technology, Shenyang 110870, P. R. China.E-mail: xiao.li@sut.edu.cn,wuxiang05@sut.edu.cn ${ }^{b}$ Key Laboratory of Superlight Materials and Surface Technology, Ministry of Education, Harbin Engineering University, Harbin 150001, P. R. China
}

capacity of $356.6 \mathrm{~mA} \mathrm{~h} \mathrm{~g}^{-1}$ at $0.4 \mathrm{~A} \mathrm{~g}^{-1}$ and maintains $80.1 \%$ of the initial capacity after 500 cycles at $2 \mathrm{~A} \mathrm{~g}^{-1} \cdot{ }^{32}$ Jia and coworkers fixed $\mathrm{VO}_{2} \cdot 0.2 \mathrm{H}_{2} \mathrm{O}$ on graphene sheets using a microwave-assisted strategy. The assembled battery shows a capacity of $423 \mathrm{~mA} \mathrm{~h} \mathrm{~g}^{-1}$ at $0.25 \mathrm{~A} \mathrm{~g}^{-1}$ and a discharge capacity retention rate of $87 \%$ after 1000 cycles at $8 \mathrm{~A} \mathrm{~g}^{-1} \cdot{ }^{33}$ In addition, $\mathrm{Na}_{1.1} \mathrm{~V}_{3} \mathrm{O}_{7.9}$ nanorods were obtained by Zhou's group. Using the obtained product as the cathode, the cells possess a capacity of $134 \mathrm{~mA} \mathrm{~h} \mathrm{~g}^{-1}$ after 1000 cycles at $5 \mathrm{~A} \mathrm{~g}^{-1}$. $^{34}$

Herein, we prepared NVO nanobelts using $\mathrm{C}_{6} \mathrm{H}_{8} \mathrm{O}_{7} \cdot \mathrm{H}_{2} \mathrm{O}$ as the binding agent. The obtained NVO as an electrode material not only maintains a stable structure during charging and discharging but also shows an energy density of 433.02 $\mathrm{W} \mathrm{h} \mathrm{kg}^{-1}$ at a power density of $420 \mathrm{~W} \mathrm{~kg}^{-1}$ at $0.3 \mathrm{~A} \mathrm{~g}^{-1}$. Furthermore, the assembled $\mathrm{NVO} / \mathrm{Zn}$ batteries deliver a high capacity of $309.4 \mathrm{~mA} \mathrm{~h} \mathrm{~g}^{-1}$ at $0.3 \mathrm{~A} \mathrm{~g}^{-1}$ and a capacity retention rate of $98.56 \%$ after 10000 cycles at $10 \mathrm{~A} \mathrm{~g}^{-1}$, suggesting their excellent rate performance.

\section{Experimental section}

\subsection{Material preparation}

All chemicals were used as purchased without further purification. Firstly, $10 \mathrm{mmol} \mathrm{NaVO}_{3}$ was added into $60 \mathrm{~mL}$ deionized water and stirred at room temperature for $40 \mathrm{~min}$. Subsequently, $8 \mathrm{mmol}_{6} \mathrm{H}_{8} \mathrm{O}_{7} \cdot \mathrm{H}_{2} \mathrm{O}$ and $20 \mathrm{mmol} \mathrm{Na}_{2} \mathrm{~S}_{2} \mathrm{O}_{8}$ were poured into the above solution and stirred for $1 \mathrm{~h}$. Finally, the clear solution was transferred into a $100 \mathrm{~mL}$ Teflon-lined autoclave and heated at $180{ }^{\circ} \mathrm{C}$ for $6 \mathrm{~h}$. After cooling to room temperature, the obtained precipitate was washed many times with deionized water. Then it was dried in an oven. 


\subsection{Structural characterization}

The morphology and element analysis of the products were studied by field emission scanning electron microscopy (FESEM, Gemini 300) and transmission electron microscopy (TEM, JEM-F200) equipped with energy dispersive spectroscopy (EDS). The crystal structure of the sample was analyzed using $\mathrm{X}$-ray diffraction (XRD, Bruker D2) and X-ray photoelectron spectroscopy (XPS, Thermo Fisher ESCALAB XI+).

\subsection{Electrochemical measurement}

The cathode, zinc anode and separator were assembled in 2032type coin cells in air. The cathode was prepared by mixing the NVO, Ketjen black (KB) and polyvinylidene fluoride (PVDF) with a weight ratio of 7:2:1 in N-methyl-l-2-pyrrolidone (NMP) solvent. The obtained slurry was subjected to magnetic stirring for $8 \mathrm{~h}$ to mix it uniformly. The slurry was coated evenly on a carbon paper as the cathode, and then placed it in a $60{ }^{\circ} \mathrm{C}$ vacuum drying oven for a night. A zinc sheet with a thickness of $100 \mu \mathrm{m}$ was used as the anode, and glass fiber was used as the intermediate separator. The devices were assembled using $4 \mathrm{M}$ $\mathrm{Zn}\left(\mathrm{CF}_{3} \mathrm{SO}_{3}\right)_{2}$ aqueous electrolyte. The cyclic voltammetry (CV) performance curves were tested in a CHI760E electrochemical workstation. The galvanostatic charge-discharge (GCD) curves, long-cycle stability and galvanostatic intermittent titration technique (GITT) were characterized by a LAND-CT3001 automatic battery tester with the voltage range of $0.2-1.6 \mathrm{~V}$. The average loading of the cathode active material is about $1.3 \mathrm{mg}$.

\section{Results and discussion}

The crystal structure of the sample was first studied by XRD. The diffraction peaks (Fig. 1a) locate at $2 \theta=8.25^{\circ}(001), 24.7^{\circ}$ (003), 25.64 ${ }^{\circ}$ (110), 33.13 ${ }^{\circ}$ (004), 33.21 ${ }^{\circ}$ (-204), 34.38 ${ }^{\circ}$ (401), $14.77^{\circ}(005), 46.87^{\circ}(-602), 50.02^{\circ}(020), 61.1^{\circ}(-712)$ and $64.32^{\circ}(-407)$. These peaks are consistent with NVO (PDF\#851407). Except these, there are no other impurity peaks, demonstrating the high purity of the prepared sample. Then, XPS was used to further investigate the oxidation states of the $\mathrm{Na}, \mathrm{V}$, and $\mathrm{O}$ elements. The high resolution XPS of $\mathrm{Na}$ 1s (Fig. 1b) only shows a sharp peak $(1071.35 \mathrm{eV})$, indicating that $\mathrm{Na}^{+}$is the only existing form of the Na element. For V 2p, as shown in Fig. 1c, the diffraction peaks of $\mathrm{V} 2 \mathrm{p}_{3 / 2}$ and $\mathrm{V} 2 \mathrm{p}_{1 / 2}$ are all fitted into $\mathrm{V}^{+5}$ and $\mathrm{V}^{+4}$. There are three diffraction peaks that appear in the XPS spectra of O 1s $(529.6 \mathrm{eV}, 530 \mathrm{eV}$, and $530.5 \mathrm{eV})$, as shown in Fig. 1d. They can be ascribed to $\mathrm{V}-\mathrm{O}, \mathrm{OH}^{-}$and low-coordination oxygen ions, respectively. ${ }^{35}$

Subsequently, we used SEM to observe the morphology of the product. It was found that the prepared NVO product shows
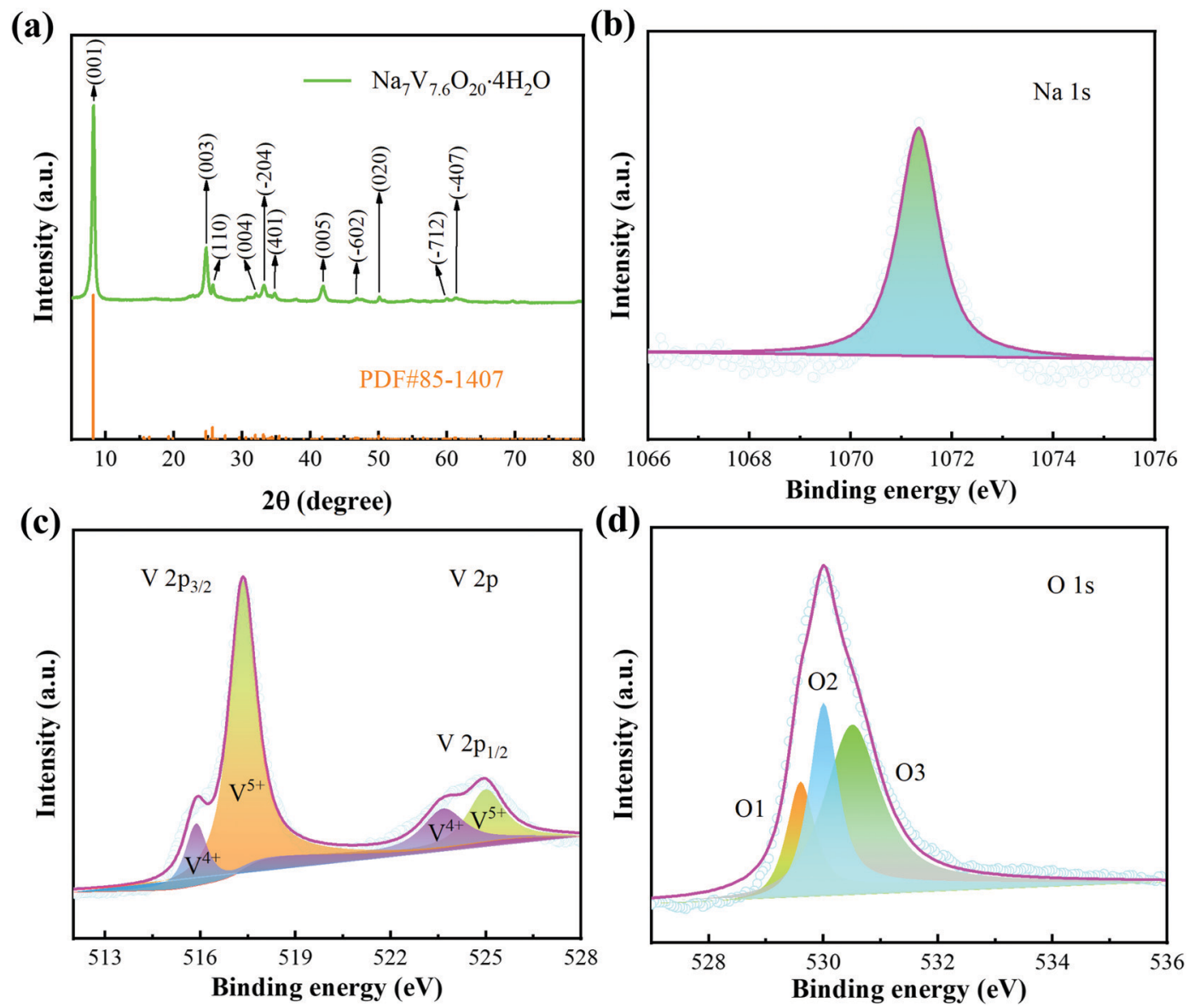

Fig. 1 Structural characterization of the samples. (a) XRD patterns. (b-d) XPS spectra of Na 1s, V 2p and O 1 s. 


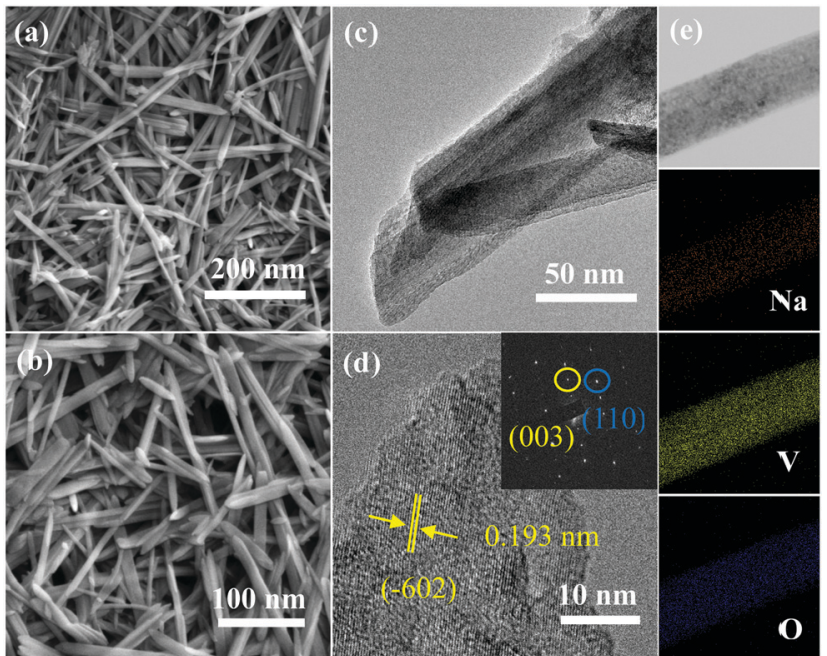

Fig. 2 Morphology and structure characterization of the samples. ( $a$ and $b$ ) SEM images. (c) TEM image. (d) HRTEM image. (e) The corresponding elemental mappings of $\mathrm{Na}, \mathrm{V}$ and $\mathrm{O}$.

a belt-like shape (Fig. 2a and b). TEM was used to further study the microstructures of the sample. Fig. $2 \mathrm{c}$ is a low magnification TEM image, revealing that the products possess a rectangular feature. The HRTEM image (Fig. 2d) show that the interplanar spacing is $0.193 \mathrm{~nm}$, which can be indexed to the $(-602)$ plane (PDF\#85-1407). The SAED image (the inset in Fig. 2d) suggests the single crystalline structure of the sample. The element mapping in Fig. 2e proves the uniform distribution of the $\mathrm{Na}$, $\mathrm{V}$, and $\mathrm{O}$ elements in the product.

In order to test the electrochemical performance characteristics of the sample, the batteries were assembled using obtained NVO as the cathode in a $4 \mathrm{M} \mathrm{Zn}\left(\mathrm{CF}_{3} \mathrm{SO}_{3}\right)_{2}$ electrolyte. Fig. 3a shows the first five cycles of the CV curves with a potential of $0.2-1.6 \mathrm{~V}$ at $0.5 \mathrm{mV} \mathrm{s}^{-1}$. The corresponding oxidation peaks locate at $0.548 \mathrm{~V}$, $0.735 \mathrm{~V}, 0.988 \mathrm{~V}, 1.061 \mathrm{~V}, 1.362 \mathrm{~V}$ and $1.432 \mathrm{~V}$. The reduction peaks appear at $1.328 \mathrm{~V}, 0.961 \mathrm{~V}, 0.82 \mathrm{~V}, 0.59 \mathrm{~V}$ and $0.397 \mathrm{~V}$. It is found that the shapes of the curves in the first cycle and the last four cycles are different, revealing that the oxidation-reduction reaction in the first circle is irreversible. The rate performance of the device is shown in Fig. 3b. As the current density varies from 0.3 to $10 \mathrm{~A} \mathrm{~g}^{-1}$, the discharge specific capacity of the device gradually decreases from 309.4 to $240.4 \mathrm{~mA} \mathrm{~h}^{-1}$. The small capacity change during whole reaction process indicates that the device shows a little capacity loss at different current densities. The GCD curves of the battery at different current densities (Fig. 3c) are consistent with the rate curves. Fig. 3d gives the cycling time dependent on the GCD curves at $1 \mathrm{~A} \mathrm{~g}^{-1}$. The results show that the capacity of the device increases with the increase in cycling time, which can be attributed to the activation behavior of NVO in the electrolyte. Moreover, the shapes of the GCD curves remain unchanged, suggesting the highly reversible redox reaction during the entire charge-discharge cycling.

The cycling stability of the NVO/Zn batteries was also tested at different current densities. The cycling tests at $1 \mathrm{~A} \mathrm{~g}^{-1}$ (Fig. 3e) show that the initial specific capacity is $298.5 \mathrm{~mA} \mathrm{~h} \mathrm{~g}^{-1}$, and the largest specific capacity of $301.5 \mathrm{~mA} \mathrm{~h} \mathrm{~g}^{-1}$ is obtained after 100 cycles. The devices can still show a specific capacity of $231.8 \mathrm{~mA} \mathrm{~h} \mathrm{~g}^{-1}$ after 300 cycles, and the capacity retention rate is $77.6 \%$. Fig. $3 \mathrm{f}$ shows the cycle performance of the battery at $5 \mathrm{~A} \mathrm{~g}^{-1}$. After 1400 cycles, the specific discharge capacity of the cell does not decrease significantly. We then studied the longcycle performance of the $\mathrm{NVO} / \mathrm{Zn}$ battery at $10 \mathrm{~A} \mathrm{~g}^{-1}$. The initial discharge capacity is $195.1 \mathrm{~mA} \mathrm{~h}^{-1}$. The capacity of the device reaches a maximum capacity of $243.5 \mathrm{~mA} \mathrm{~h} \mathrm{~g}^{-1}$ at 3000 cycles and then decreases gradually to $192.3 \mathrm{~mA} \mathrm{~h} \mathrm{~g}^{-1}$ at 10000 cycles, as shown in Fig. 3g. The capacity retention rate is $98.56 \%$ during this process. The Coulombic efficiency always remains above 99\%. The rate performance and cycling stability is better than several reported vanadium-based materials (Table 1). ${ }^{36-42}$

To evaluate the electrochemical reaction kinetics of the $\mathrm{NVO} / \mathrm{Zn}$ battery, the $\mathrm{CV}$ curves were tested at different scan rates (from 0.6 to $1 \mathrm{mV} \mathrm{s}^{-1}$ ) (Fig. 4a). The integral areas of the $\mathrm{CV}$ curves increase as the scanning speed rises, demonstrating the multi-step process of the deintercalation/intercalation of $\mathrm{Zn}^{2+}$. In addition, the oxidation and reduction peaks shift to the high voltage and low voltage regions, respectively. Fig. $4 \mathrm{~b}$ is obtained by fitting the currents at different redox peaks, where peaks $1,2,3$, and 4 correspond to their respective ones in Fig. 4a. The correlation between the peak current $(i)$ and scan rate $(v)$ abide by the following formula:

$$
i=a v^{b}
$$

When the $b$ value is 0.5 , the charge storage can be expressed as diffusion control behavior. When $b=1$, it is thought to be a capacitive process. The calculated b values of peaks $1,2,3$, and 4 are $0.6574,0.9529,0.5976$, and 0.8396 , respectively. The value of $\mathrm{b}$ is between 0.5 and 1 , indicating that pseudo-capacitance is dominant during the charge storage process. The ratio of surface and diffusion control contribution can be obtained according to the formula:

$$
i=k_{1} v+k_{2} v^{1 / 2}
$$

where $k_{1}$ and $k_{2}$ are constants and $k_{1} v$ and $k_{2} v^{1 / 2}$ are the surface control and diffusion control contribution, respectively. ${ }^{43}$ Fig. $4 \mathrm{c}$ shows a histogram of the surface and diffusion controlled ratios. When the scan rate increases from 0.6 to $1 \mathrm{mV} \mathrm{s}^{-1}$, the capacitance contribution gradually increases from $65.1 \%$ to $71.6 \%$. The results show that the devices possess high reaction kinetics and rate performance.

The diffusion coefficient of $\mathrm{Zn}^{2+}\left(\mathrm{D}_{\mathrm{Zn}}{ }^{2+}\right)$ of the NVO electrode was then calculated from the obtained GITT curves. Firstly, the $\mathrm{NVO} / \mathrm{Zn}$ batteries are charged or discharged at $0.3 \mathrm{~A} \mathrm{~g}^{-1}$ for 3 $\mathrm{min}$, and then rested for $7 \mathrm{~min}$ to make the voltage reach steady. This process is repeated to obtain the GITT curves during battery operation (Fig. 4d). The calculated $\mathrm{D}_{\mathrm{Zn}}{ }^{2+}$ is shown in Fig. 4e according to the formula:

$$
\mathrm{D}_{\mathrm{zn}^{2+}}=\frac{4}{\pi \tau}\left(\frac{\mathrm{mV}}{\mathrm{MS}}\right)^{2}\left(\frac{\Delta \mathrm{Es}}{\Delta \mathrm{E} \tau}\right)^{2}
$$


(a)

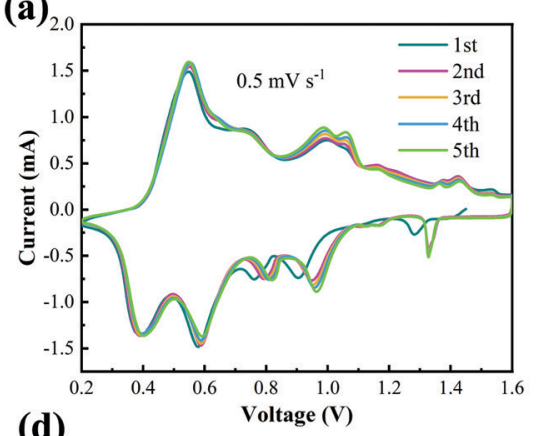

(d)

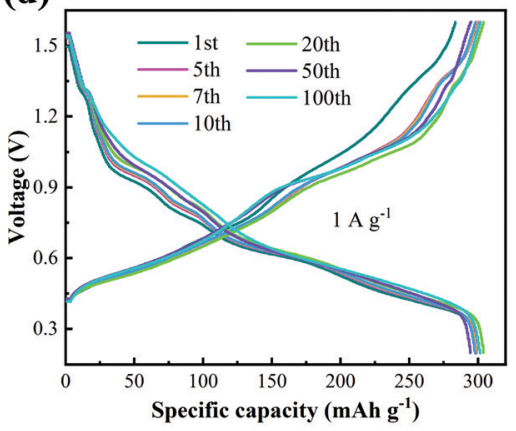

(b)

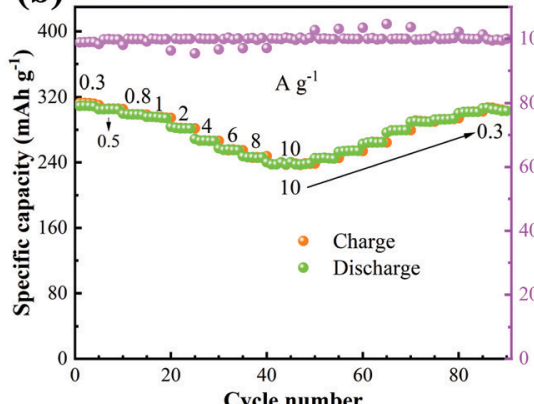

(e)

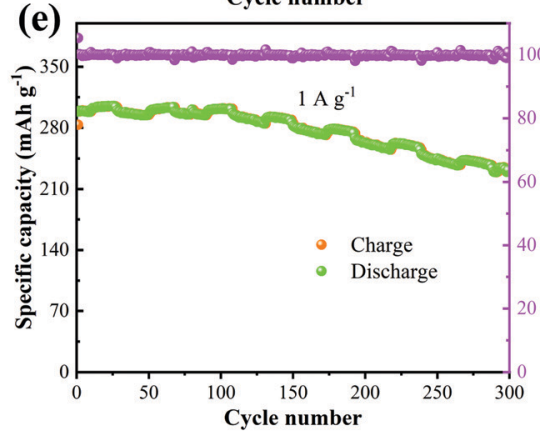

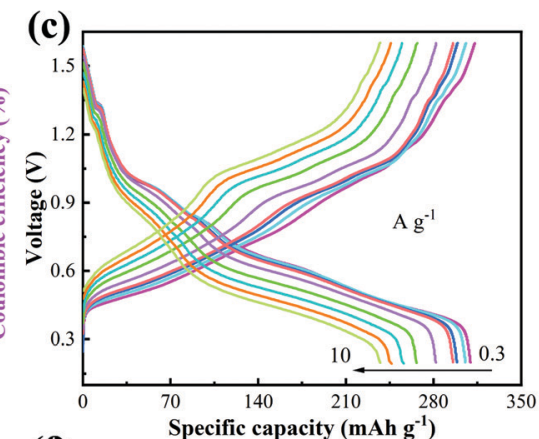

(f)

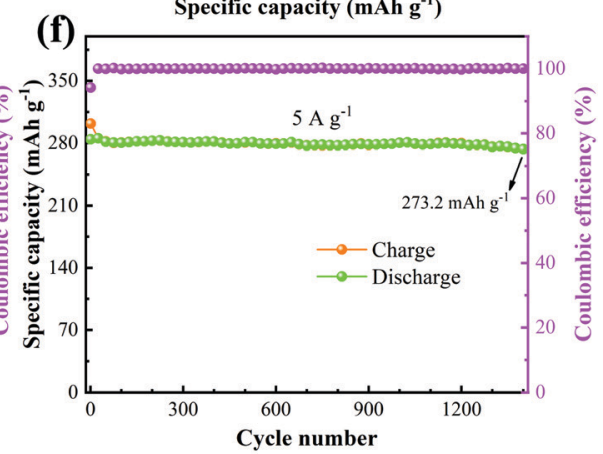

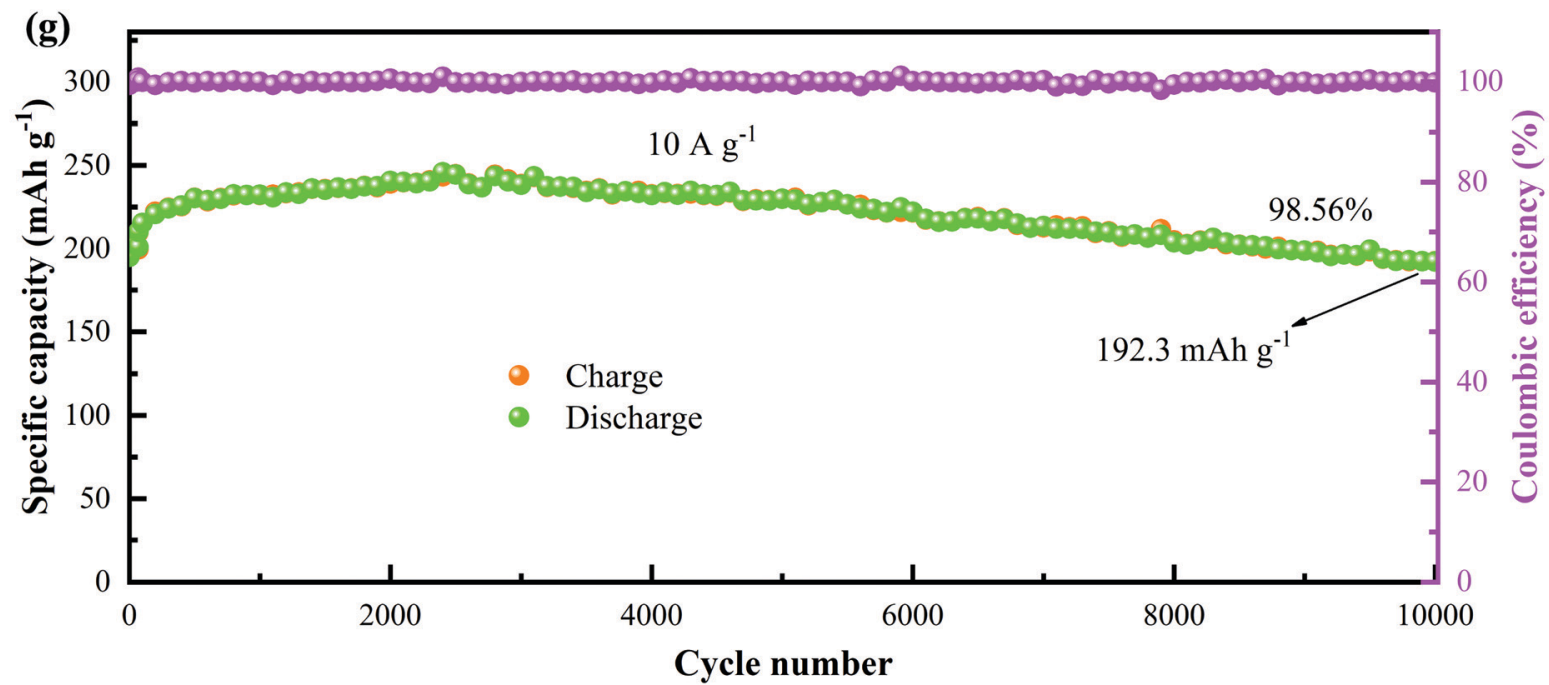

Fig. 3 Electrochemical performance of the electrodes. (a) CV curves of the first 5 cycles at $0.5 \mathrm{mV} \mathrm{s}^{-1}$, (b and c) rate capability and GCD curves at different current densities, (d) GCD curves of various cycles at $1 \mathrm{~A} \mathrm{~g}^{-1}$, (e) cycling performance at $1 \mathrm{~A} \mathrm{~g}^{-1}$, (f) cycling performance at $5 \mathrm{~A} \mathrm{~g}$. , and (g) longterm cycles at $10 \mathrm{~A} \mathrm{~g}^{-1}$.

Table 1 Rate performance and cycle stability of different cathodes

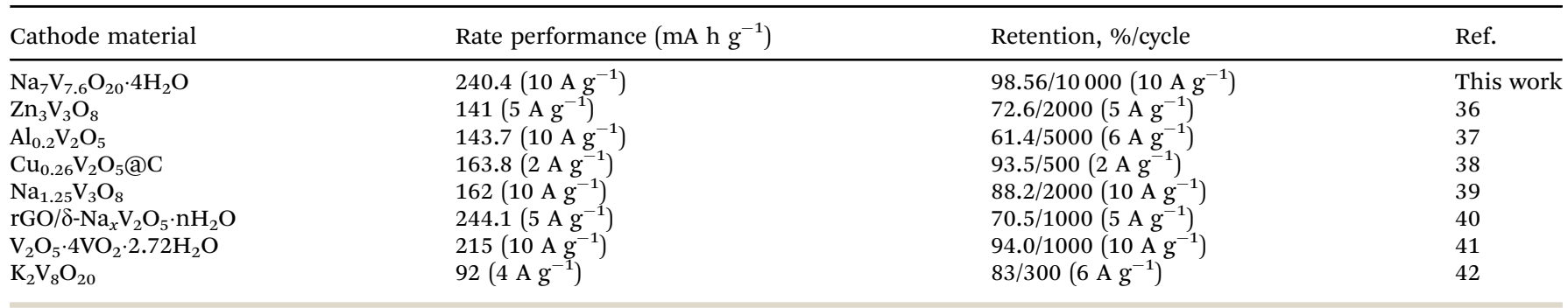

where $\tau$ is the duration time (s) of charging or discharging, $\mathrm{m}$ is the loading of the active material on the cathode $(\mathrm{g}), \mathrm{V}$ and $\mathrm{M}$ are the molar volume $\left(\mathrm{cm}^{3} \mathrm{~mol}^{-1}\right)$ and molecular weight $\left(\mathrm{g} \mathrm{mol}^{-1}\right)$ of the active material, respectively, $\mathrm{S}$ is the contact 
(a)
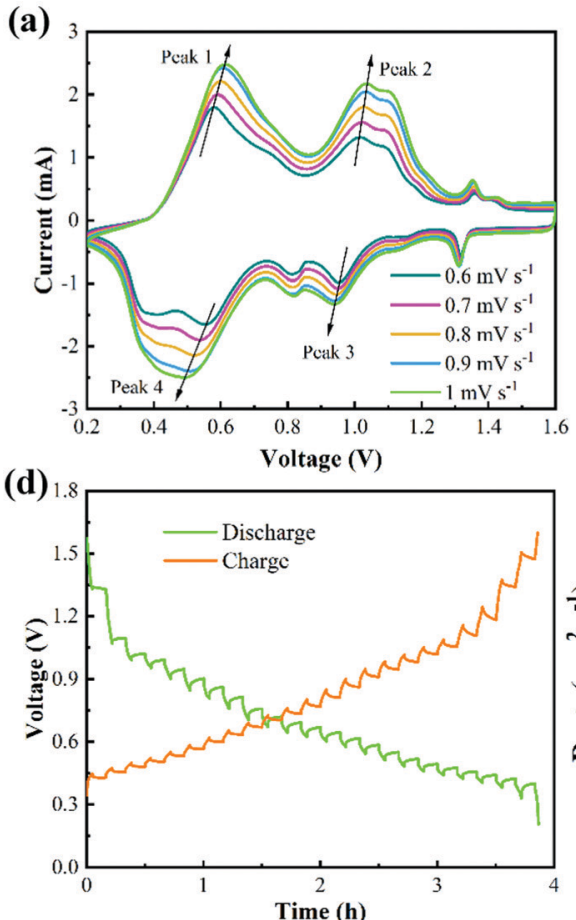

(b)
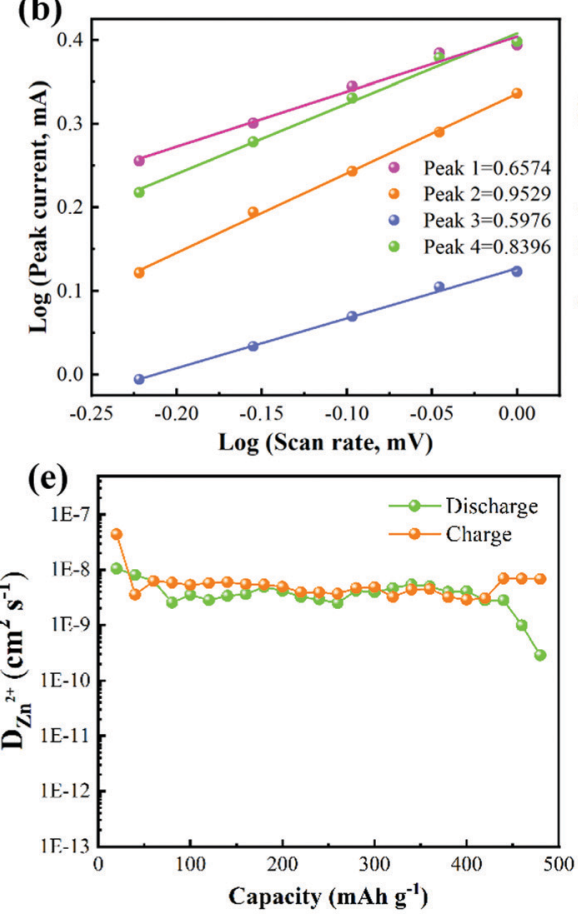
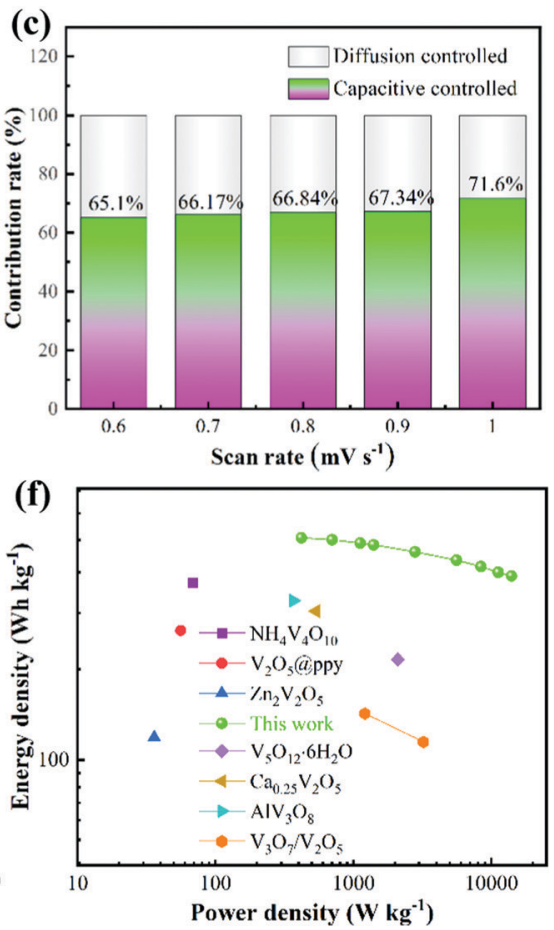

Fig. 4 The electrochemical reaction kinetics of the batteries. (a) CV curves at various scan rates, (b) the fitting plots of log (i) and log (v), (c) the capacitive contribution ratio at various scan rates, (d) GITT curves, (e) $\mathrm{Zn}^{2+}$ diffusion coefficient, and (f) Ragone plot.

area between the electrode and the electrolyte, $\Delta \mathrm{Es}$ is the variation between the initial voltage and the steady-state voltage, and $\Delta E \tau$ is the variation of the battery voltage during titration. ${ }^{44}$ In our work, the range of $\mathrm{D}_{\mathrm{Zn}}{ }^{2+}$ during discharge is between $10^{-8}$ and $10^{-10} \mathrm{~cm}^{2} \mathrm{~s}^{-1}$, and the value of $\mathrm{D}_{\mathrm{Zn}}{ }^{2+}$ drops to the lowest when the discharge reaches $0.2 \mathrm{~V}$. It shows that
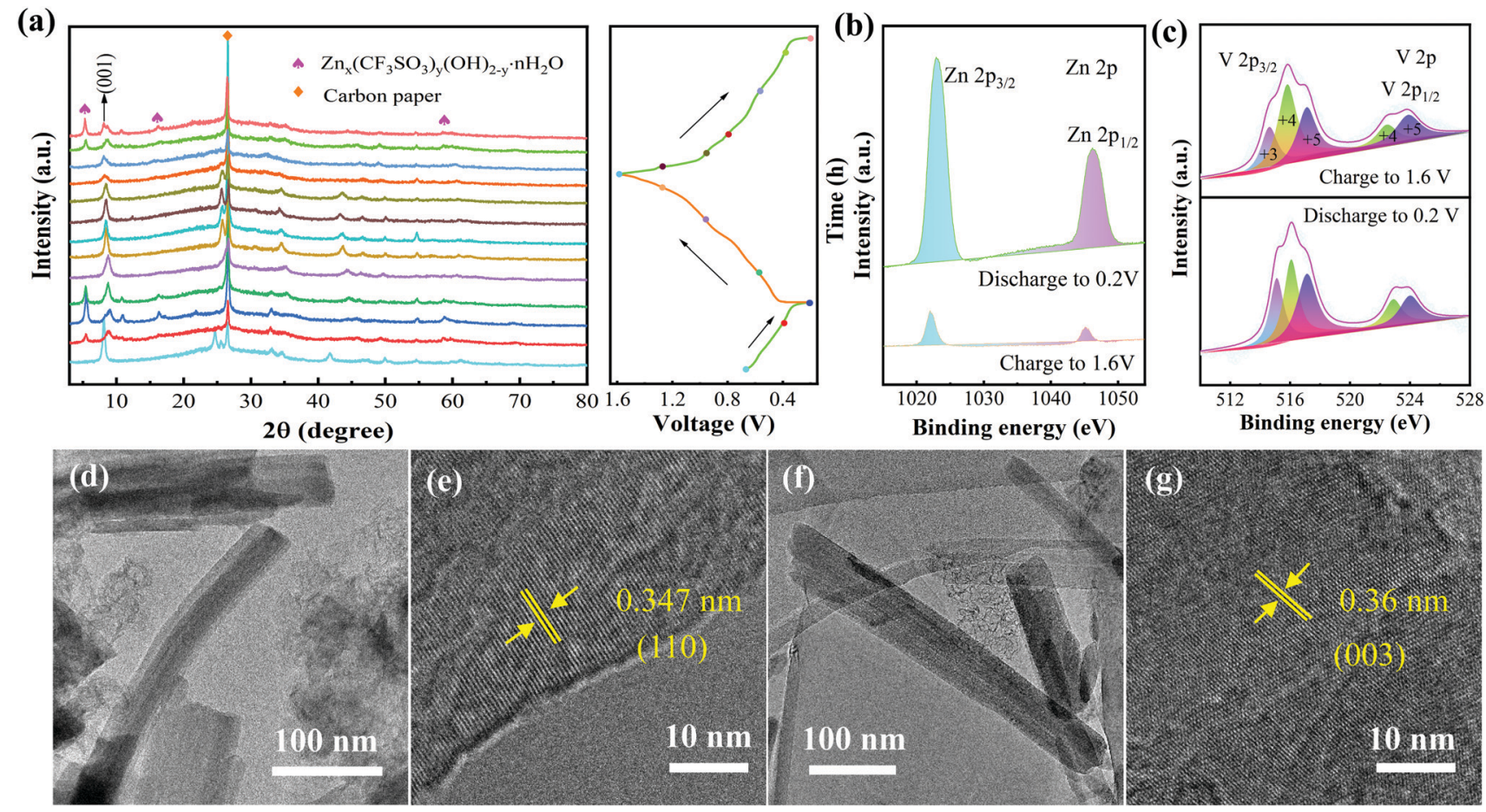

Fig. 5 The reaction mechanism of the batteries. (a) Ex situ XRD patterns at various charge/discharge states. (b and $c$ ) XPS of Zn $2 p$ and $V 2 p$ at the charge-discharge states. $(\mathrm{d}-\mathrm{g})$ TEM images of the sample discharging at $0.2 \mathrm{~V}$ and charging at $1.6 \mathrm{~V}$. 
the intercalation of $\mathrm{Zn}^{2+}$ is beneficial to the enhancement of electrostatic repulsion inside the NVO. ${ }^{45}$ The value of $\mathrm{D}_{\mathrm{Zn}}{ }^{2+}$ during charging is between $10^{-9}$ and $10^{-10} \mathrm{~cm}^{2} \mathrm{~s}^{-1}$, which is better than the reported vanadium-based cathode. ${ }^{46,47}$ The battery presents an energy density of $433.02 \mathrm{~W} \mathrm{~h} \mathrm{~kg}^{-1}$ at a power density of $420 \mathrm{~W} \mathrm{~kg}^{-1}$ at $0.3 \mathrm{~A} \mathrm{~g}^{-1}$. When the power density reaches $14000 \mathrm{~W} \mathrm{~kg}^{-1}$ at $10 \mathrm{~A} \mathrm{~g}^{-1}$, it still maintains an energy density of $336.56 \mathrm{~W} \mathrm{~h} \mathrm{~kg}{ }^{-1}$. The Ragone plot (Fig. 4f) lists the energy densities of several vanadium-based materials $\left(\mathrm{NH}_{4} \mathrm{~V}_{4} \mathrm{O}_{10}{ }^{48} \quad \mathrm{~V}_{2} \mathrm{O}_{5}\right.$ @ppy, ${ }^{49} \quad \mathrm{Zn}_{2} \mathrm{~V}_{2} \mathrm{O}_{7},{ }^{50} \quad \mathrm{~V}_{5} \mathrm{O}_{12} \cdot 6 \mathrm{H}_{2} \mathrm{O}{ }^{51}$ $\mathrm{Ca}_{0.25} \mathrm{~V}_{2} \mathrm{O}_{5},{ }^{52} \mathrm{AlV}_{3} \mathrm{O}_{9}{ }^{53}$ and $\left.\mathrm{V}_{3} \mathrm{O}_{7} / \mathrm{V}_{2} \mathrm{O}_{5}{ }^{54}\right)$. It is obvious that the energy density and power density of the obtained NVO are better than those cathodes as well as some other materials. ${ }^{55-57}$

Finally, we investigated the dynamic migration process of $\mathrm{Zn}^{2+}$. The ex situ XRD patterns (Fig. 5a) indicate the structural evolution of the NVO electrode during charging and discharging. It can be seen that the diffraction peaks of the (001) crystal plane show an angle red shift after the first discharge to $0.2 \mathrm{~V}$. It reveals the strong electrostatic force between the intercalation of $\mathrm{Zn}^{2+}$ and the cathode during the first discharge. The (001) plane returns to its original state gradually with the process of charging to $1.6 \mathrm{~V}$. The angles of the (001) plane only slightly shift when the second discharge is performed, indicating that the intercalation of $\mathrm{Zn}^{2+}$ does not significantly change the crystal plane spacing. It further proves the excellent structural stability of the electrode materials during the charge-discharge process. Besides this, there are several new diffraction peaks during the first discharge process, revealing the formation of interphase $\mathrm{Zn}_{x}\left(\mathrm{CF}_{3} \mathrm{SO}_{3}\right)_{y}(\mathrm{OH})_{2-y .}{ }^{58}$ During the subsequent charging to $1.6 \mathrm{~V}$, the diffraction peaks of the interphase gradually disappear, indicating the high reversibility of the interphase during the entire cycle.

To study the valence state and surface composition of the NVO electrode, ex situ XPS tests were performed on the cathode in different charging/discharging states. As shown in Fig. 5b, the strong signals of $\mathrm{Zn} \mathrm{2p_{3/2 }}(1022.9 \mathrm{eV})$ and $\mathrm{Zn} \mathrm{2p_{1/2 }}(1045.9 \mathrm{eV})$ appear during the discharge to $0.2 \mathrm{~V}$. The peak intensity decreased significantly during charging to $1.6 \mathrm{~V}$, demonstrating that $\mathrm{Zn}$ ions are successfully inserted into the cathode. Fig. $5 \mathrm{c}$ shows the high-resolution XPS spectra of V 2p at the charging and discharging states. The peaks at $\mathrm{V} 2 \mathrm{p}_{3 / 2}$ can be fitted by $\mathrm{V}^{+3}$ $(515.5 \mathrm{eV}), \mathrm{V}^{+4}(516 \mathrm{eV})$ and $\mathrm{V}^{+5}(516.8 \mathrm{eV})$, while the peaks at $\mathrm{V}$ $2 \mathrm{p}_{1 / 2}$ are only fitted by $\mathrm{V}^{+4}(522.15 \mathrm{eV})$ and $\mathrm{V}^{+5}(523.75 \mathrm{eV})$. In the fully charged and discharged states, the peak areas change at different valence states. In discharging to $0.2 \mathrm{~V}$, the $\mathrm{V}^{+4}$ signals weaken and the signals of $\mathrm{V}^{+3}$ and $\mathrm{V}^{+5}$ strengthen. The signals of $\mathrm{V}^{+3}$ and $\mathrm{V}^{+5}$ gradually increase and the signal of $\mathrm{V}^{+4}$ decreases when charging to $1.6 \mathrm{~V}$. It shows that the oxidation-reduction reactions of the $\mathrm{V}$ element are highly reversible during the cycle. ${ }^{59}$ The structural characteristics of the electrode were tested again using TEM. Fig. $5 \mathrm{~d}$ and e and Fig. $5 \mathrm{f}$ and $\mathrm{g}$ show the TEM images of the electrode discharged to $0.2 \mathrm{~V}$ and charged to $1.6 \mathrm{~V}$, respectively. During the discharge to $0.2 \mathrm{~V}$, the structure of the NVO is maintained well and the interplanar spacing of the (110) plane is $0.347 \mathrm{~nm}$, suggesting that the intercalation of $\mathrm{Zn}^{2+}$ does not obviously change the interplanar spacing. The interplanar spacing of the (003) plane is $0.36 \mathrm{~nm}$ after the release of $\mathrm{Zn}^{2+}$, proving the excellent structural stability of the NVO products.

\section{Conclusion}

In summary, we have prepared NVO nanobelts using a simple one-step hydrothermal strategy. The obtained NVO product can maintain superior structural stability after the intercalation of zinc ions. It also enhances the transfer rate of $\mathrm{Zn}^{2+}$ inside the cathode. The assembled batteries show high rate performance, fast electrochemical reaction kinetics and a long-term cycle lifespan. The subsequent TEM observation of the electrode materials proves that the NVO electrode maintains unchanged structural characteristics during the charge-discharge process. It suggests that the battery assembled by the as-prepared product can be utilized in future portable micro/nanodevices.

\section{Author contributions}

Chengkang Luo: conceptualization, methodology, software, data processing, writing - original draft preparation. Chengkang Luo and Li Xiao: visualization, investigation. Xiang Wu: validation, supervision, writing - review \& editing.

\section{Conflicts of interest}

The authors declare that they have no known competing financial interests.

\section{Acknowledgements}

The work is supported by the National Natural Science Foundation of China (No. 52172218), the Open Project Program of Key Laboratory of Superlight Materials and Surface Technology, Ministry of Education, Harbin Engineering University (HEU10202118).

\section{References}

1 J. Ming, J. Guo, C. Xia, W. X. Wang and H. N. Alshareef, Mater. Sci. Eng., R, 2019, 135, 58-84.

2 L. L. Fan, Z. H. Li and W. M. Kang, ACS Sustainable Chem. Eng., 2021, 9, 5095-5104.

3 X. Y. Liang, L. J. Yan, W. P. Li, Y. C. Bai, C. Zhu, Y. J. Qiang, B. X. Xiong, B. Xiang and X. F. Zou, Nano Energy, 2021, 87, 106164.

4 X. Wang, Z. C. Y. Zhang, B. J. Xi, W. H. Chen, Y. X. Jia, J. K. Feng and S. L. Xiong, ACS Nano, 2021, 15, 9244-9272.

5 J. Zhou, A. Q. Dong, L. Du, C. C. Yang, L. Ye, X. Wang, L. J. Zhao and Q. Jiang, Chem. Eng. J., 2021, 421, 127770.

6 C. Liu, X. Wu and B. Wang, Chem. Eng. J., 2020, 392, 123651.

7 Y. Ru, S. S. Zheng, H. G. Xue and H. Pang, Mater. Today Chem., 2021, 21, 100513.

8 Y. Liu and X. Wu, J. Energy Chem., 2021, 56, 223-237.

9 L. S. Zhang, J. S. Hu, B. Zhang, J. Liu, H. Z. Wan, L. Miao and J. J. Jiang, J. Mater. Chem. A, 2021, 9, 7631-7639. 
10 T. T. Wei, P. P. Peng, S. Y. Qi, Y. R. Zhu and T. F. Yi, J. Energy Chem., 2021, 57, 169-188.

11 Z. Q. Guo, S. Q. Zhao, T. X. Li, D. W. Su, S. G. Guo and G. X. Wang, Adv. Energy Mater., 2020, 10, 1903591.

12 Y. C. Tang, X. J. Li, H. M. Lv, W. L. Wang, Q. Yang, C. Y. Zhi and H. F. Li, Angew. Chem., Int. Ed., 2021, 60, 5443-5452.

13 B. F. Ji, H. Y. He, W. J. Yao and Y. B. Tang, Adv. Mater., 2020, 33, 2005501.

14 C. P. Han, H. F. Li, Y. Li, J. X. Zhu and C. Y. Zhi, Nat. Commun., 2021, 12, 2400.

15 D. Chen, M. J. Lu, D. Cai, H. Yang and W. Han, J. Energy Chem., 2021, 54, 712-726.

16 X. R. Wang, G. Q. Tan, Y. Bai, F. Wu and C. Wu, Electrochem. Energy Rev., 2020, 4, 35-66.

17 Y. Liu and X. Wu, Chin. Chem. Lett., 2021, DOI: 10.1016/ j.cclet.2021.08.081.

18 W. B. Liu, X. Y. Zhang, Y. F. Huang, B. Z. Jiang, Z. W. Chang, C. G. Xu and F. Y. Kang, J. Energy Chem., 2021, 56, 365-373.

19 Y. Liu and X. Wu, Nano Energy, 2021, 86, 106124.

20 N. Liu, B. Li, Z. X. He, L. Dai, H. Y. Wang and L. Wang, J. Energy Chem., 2021, 59, 134-159.

21 G. Y. Du and H. Pang, Energy Storage Mater., 2021, 36, 387-408.

22 T. Sun, Z. J. Li, Y. F. Zhi, Y. J. Huang, H. J. Fan and Q. C. Zhang, Adv. Funct. Mater., 2021, 31, 2010049.

23 W. C. Bi, G. H. Gao, G. M. Wu, M. Atif, M. S. AlSalhi and G. Z. Cao, Energy Storage Mater., 2021, 40, 209-218.

24 Y. Y. Liu, T. T. Lv, H. Wang, X. T. Guo, C. S. Liu and H. Pang, Chem. Eng. J., 2021, 417, 128408.

25 Y. Li, D. H. Zhang, S. Z. Huang and H. Y. Yang, Nano Energy, 2021, 85, 105969.

26 Y. Liu, Y. Liu, Y. Yamauchi, Z. A. Alothman, Y. V. Kaneti and $\mathrm{X}$. Wu, Batteries Supercaps, 2021, DOI: 10.1002/ batt.202100172.

27 Y. Liu, P. Hu, H. Liu, X. Wu and C. Zhi, Mater. Today Energy, 2020, 17, 100431.

28 X. Q. Shan, S. W. Kim, A. M. M. Abeykoon, G. Kwon, D. Olds and X. W. Teng, ACS Appl. Mater. Interfaces, 2020, 12, 54627-54636.

29 F. Wan, S. Huang, H. M. Cao and Z. Q. Niu, ACS Nano, 2020, 14, 6752-6760.

30 Y. Zhang, F. Wan, S. Huang, S. Wang, Z. Q. Niu and J. Chen, Nat. Commun., 2020, 11, 2199.

31 Q. F. Li, X. H. Rui, D. Chen, Y. Z. Feng, N. Xiao, L. Y. Gan, Q. Zhang, Y. Yu and S. M. Huang, Nano-Micro Lett., 2020, 12, 67.

32 X. W. Wang, L. Q. Wang and B. Zhang, J. Energy Chem., 2021, 59, 126-133.

33 D. D. Jia, K. Zheng and M. Song, Nano Res., 2020, 13, 215-224.

34 B. H. She, L. T. Shan, H. J. Chen, J. Zhou, X. Gun, G. Z. Fang, X. X. Cao and S. Q. Liang, J. Energy Chem., 2019, 37, 172-175.

35 H. Luo, B. Wang, C. L. Wang, F. D. Wu, F. Jin, B. W. Cong, Y. Ning, Y. Zhou, D. L. Wang, H. K. Liu and S. X. Dou, Energy Storage Mater., 2020, 33, 390-398.

36 J. Wu, Q. Kuang, K. Zhang, J. J. Feng, C. M. Huang, J. J. Li, Q. H. Fan, Y. Z. Dong and Y. M. Zhao, Energy Storage Mater., 2021, 41, 297-309.
37 Q. Pang, W. He, X. Y. Yu, S. Y. Yang, H. N. Zhao, Y. Fu, M. M. Xing, Y. Tian, X. X. Luo and Y. J. Wei, Appl. Surf. Sci., 2021, 538, 148043.

38 X. W. Wang, B. Zhang, J. M. Feng, L. Q. Wang, B. Wu, J. F. Zhang, X. Ou, F. Hou and J. Liang, Sustainable Mater. Technol., 2020, 26, e00236.

39 D. Xie, F. Hu, X. Yu, F. H. Cui, G. H. Song and K. Zhu, Chin. Chem. Lett., 2020, 31, 2268-2274.

40 W. J. Zhou, J. Z. Chen, C. L. He, M. F. Chen, X. W. Xu, Q. H. Tian, J. L. Xu and C. P. Wong, Electrochim. Acta, 2019, 321, 134689.

41 T. T. Lv, Y. Y. Liu, H. Wang, S. Y. Yang, C. S. Liu and H. Pang, Chem. Eng. J., 2021, 411, 128533.

42 B. Y. Tang, G. Z. Fang, J. Zhou, L. B. Wang, Y. P. Lei, C. Wang, T. Q. Lin, Y. Tang and S. Q. Liang, Nano Energy, 2018, 51, 579-587.

43 Y. Liu and X. Wu, Nano Energy, 2021, 86, 106124.

44 H. Z. Chen, H. G. Qin, L. L. Chen, J. Wu and Z. H. Yang, J. Alloys Compd., 2020, 842, 155912.

45 J. W. Lai, H. H. Zhu, X. P. Zhu, H. Koritala and Y. Wang, ACS Appl. Energy Mater., 2019, 2, 1988-1996.

46 D. C. He, Y. Q. Peng, Y. C. Ding, X. X. Xu, Y. Huang, Z. Q. Li, X. X. Zhang and L. H. Hu, J. Power Sources, 2021, 484, 229284.

47 Y. K. Li, Z. M. Huang, P. K. Kalambate, Y. Zhong, Z. M. Huang, M. L. Xie, Y. Shen and Y. H. Huang, Nano Energy, 2019, 60, 752-759.

48 Q. F. Li, X. H. Rui, D. Chen, Y. Z. Feng, N. Xiao, L. Y. Gan, Q. Zhang, Y. Yu and S. M. Huang, Nano-Micro Lett., 2020, $12,67$.

49 X. H. Qin, X. Y. Wang, J. C. Sun, Q. Q. Lu, A. Omar and D. Mikhailova, Front. Energy Res., 2020, 8, 199.

50 B. Sambandam, V. Soundharrajan, S. Kim, M. H. Alfaruqi, J. Jo, S. Kim, V. Mathew, Y. K. Sun and J. Kim, J. Mater. Chem. A, 2018, 6, 3850-3856.

51 N. Zhang, M. Jia, Y. Dong, Y. Y. Wang, J. Z. Xu, Y. C. Liu, L. F. Jiao and F. Y. Cheng, Adv. Funct. Mater., 2019, 29, 1807331.

52 C. Xia, J. Guo, P. Li, X. X. Zhang and H. N. Alshareef, Angew. Chem., Int. Ed., 2018, 57, 3943-3948.

53 G. Y. Liu, Y. Xiao, W. W. Zhang, W. Tang, C. L. Zuo, P. P. Zhang, S. J. Dong and P. Luo, Nanotechnology, 2021, 32, 315405.

54 H. Z. Chen, L. L. Chen, J. L. Meng, Z. H. Yang, J. Wu, Y. Rong, L. Deng and Y. D. Shi, J. Power Sources, 2020, 474, 228569.

55 D. L. Chao, C. Zhu, M. Song, P. Liang, X. Zhang, N. H. Tiep, H. F. Zhao, J. Wang, R. M. Wang, H. Zhang and H. J. Fan, Adv. Mater., 2018, 30, 1803181.

56 M. Song, H. Tan, D. L. Chao and H. J. Fan, Adv. Funct. Mater., 2018, 28, 1802564.

57 D. L. Chao, W. H. Zhou, F. X. Xie, C. Ye, H. Li, M. Jaroniec and S. Z. Qiao, Sci. Adv., 2020, 6, eaba4098.

58 N. Qiu, Z. M. Yang, Y. Wang, Y. M. Zhu and W. Liu, Chem. Commun., 2020, 56, 9174-9177.

59 D. Chen, M. J. Lu, B. R. Wang, H. F. Cheng, H. Yang, D. Cai, W. Han and H. J. Fan, Nano Energy, 2021, 83, 105835. 